\title{
A estatística e o desprendimento de convenções acadêmicas: o caso da saúde
}

\author{
Maurício Bonatto Machado de Castilhos*
}

O processo de desenvolvimento do trabalho científico é baseado em problemáticas existentes na área do conhecimento que merecem esclarecimentos. Assim, objetivos e justificativas são traçados a fim de explicar o comportamento de determinado problema. Considerando o contexto do desenvolvimento do pensamento científico, o pesquisador precisa de métodos eficazes que possibilitem a execução de um planejamento experimental que satisfaça tais objetivos, além de permitir que os dados coletados sejam representativos de uma população alvo.

Diante disso, a estatística é a ciência que promove ferramentas adequadas para que o planejamento obedeça certos parâmetros delimitados e/ou limitados pela pesquisa e possibilite que os dados sejam avaliados com a finalidade de obter resultados que respondam aos objetivos propostos. Nesse contexto, o pesquisador da saúde, na maioria dos casos, depara-se com conceitos que lhe são apresentados como meras convenções entre pesquisadores da área, dentre elas conceitos de estudos retrospectivos, longitudinais, transversais, descritivos e analíticos.

Até que ponto tais convençóes são importantes e relevantes para o desenvolvimento e execução de um projeto acadêmico? No âmbito dos conceitos estatísticos, o planejamento expe- rimental direciona a análise de dados qualitativos e/ou quantitativos. Independentemente de o estudo ser retrospectivo, descritivo, analítico, transversal ou longitudinal, são essas duas opçóes que determinam a análise estatística.

É importante salientar que o pesquisador deve apresentar conhecimento sobre as vantagens e desvantagens de se optar por um delineamento experimental que esteja centrado na coleta de dados qualitativos. Muitos trabalhos vinculados à qualidade de vida de pacientes são determinados por variáveis de caráter mais qualitativo do que quantitativo e esse é um exemplo corriqueiro que ocorre nos projetos acadêmicos da área da saúde. Nesse contexto, autores consagrados elaboram metodologias para transformar dados que inicialmente seriam qualitativos em quantitativos, visto que a visão estatística quantitativa é significativamente ampla e rica no que se refere ao leque de possibilidades para revelar evidências sobre comportamento de um determinado grupo alvo de pacientes.

Portanto, desconsidera-se o propósito de tornar a discussão tendenciosa, visto que seria inoportuno. A opção por dados quantitativos sugere, de certo modo, maior gama de evidências que servirão de base para o enriquecimento da discussão dos resultados obtidos, respeitando os objetivos propostos. Apesar de a aplicação

*Engenheiro de Alimentos graduado pela Universidade Estadual Paulista "Júlio de Mesquita Filho" - Instituto de Biociências, Letras e Ciências Exatas de São José do Rio Preto (Ibilce-Unesp) (2009), Mestre e Doutorando em Engenharia e Ciência de Alimentos pela mesma instituição. Experiência na aplicação de conceitos e técnicas estatísticas desde o planejamento experimental à análise de dados através de abordagens uni e multivariadas. Possui mais de 90 trabalhos de assessoria estatística de projetos acadêmicos de graduação e pós-graduação, sendo a maioria deles vinculados à área da saúde. E-mail: mbonattosp@yahoo.com.br 
de técnicas multivariadas ser uma alternativa à aplicação de técnicas univariadas, as quais apresentam certa limitação quando se trata de dados qualitativos. A crescente quantificação das variáveis envolvidas em projetos acadêmicos comprova que os pesquisadores analisam a estatística não mais como um "bicho de sete cabeças", mas como uma ferramenta que viabiliza a busca e a sugestáo de resultados por meio de pressuposições ou inferências, amostrais ou populacionais, a fim de engrandecer o mundo acadêmico por intermédio da literal contribuição científica pura e aplicada.

Assim sendo, antes de julgar se o projeto acadêmico é descritivo, analítico, transversal ou longitudinal - o que não passa de mera convenção - o pesquisador deve avaliar o tipo de dado que será coletado, ou seja, se tal dado apresentará embasamento para atender aos objetivos propostos, e se a metodologia empregada será suficientemente adequada para que eles sejam alcançados. A etapa mais importante do desenvolvimento do pensamento científico é o delineamento experimental que possibilita a análise de limitaçóes impostas pela pesquisa, visando eliminar ou minimizar, ao máximo, os inerentes vieses do projeto acadêmico.

À vista disso, em meio à trivialização da qualidade científica, que preconiza quantidade e minimiza a qualidade, é preciso despir-se de convençóes acadêmicas e optar pela objetividade. Independentemente de valores $P$, níveis de significância ou estatísticas descritivas. $\mathrm{O}$ "fazer ciência" está diretamente relacionado ao delineamento experimental realizado com esmero, que é a chave para obter resultados que sirvam de base para a evolução científica. Tratando-se de ciência: menos também é mais. 